\title{
Value of optical coherence tomography in the
} detection of macular pathology before the removal of silicone oil

This article was published in the following Dove Press journal:

Clinical Ophthalmology

19 January 2016

Number of times this article has been viewed

Mohammad Ahmad Rashad

Ahmed Abdel Aliem

Mohamed

Asmaa Ismail Ahmed

Department of Ophthalmology, Faculty of Medicine, Ain Shams University, Cairo, Egypt
Correspondence: Mohammad Ahmad Rashad

Ain Shams University, 79 Othman

Buildings, Ali Amen Street, Nasr City,

Cairo, Egypt

Tel +20 I2 23463327

Email mohammadahmadrashadeyelaser@ gmail.com
Purpose: To assess the pathological macular changes with optical coherence tomography (OCT) before the removal of silicone oil $(\mathrm{SiO})$ in eyes that had undergone pars plana vitrectomy for complicated forms of retinal detachment (RD).

Patients and methods: Subjects included 48 patients ( 51 eyes) with complicated RD including proliferative vitreoretinopathy, proliferative diabetic retinopathy, recurrent $\mathrm{RD}$, penetrating trauma, uveitis, giant retinal tears, and macular holes. All the eyes had undergone SiO injection. Furthermore, all eyes had been planned for the removal of SiO 6-12 months after the primary surgery. Finally, all eyes had a fundus examination and OCT examination before the silicone oil removal.

Results: OCT findings indicated epiretinal membrane in $41 \%$ of the eyes, macular edema in $17 \%$, macular detachment in $13.5 \%$, macular thinning in $13.5 \%$, macular holes in $10 \%$, and subretinal membranes in $2 \%$. Preoperative OCT was normal in only $12 \%$ of the eyes, while a clinical fundus examination was normal in 43\% $(P<0.001)$. Eyes with normal OCT had significantly better mean $\log$ MAR $(0.35)$ than eyes with pathological changes detected through OCT $(1.28 ; P<0.001)$. Surgical modifications were made during the removal of $\mathrm{SiO}$ in $74.5 \%$ of the eyes.

Conclusion: OCT detected significantly more pathological changes than a clinical fundus examination. This had an impact on both surgical step modification during the removal of $\mathrm{SiO}$ and predictability of visual outcome after the removal of $\mathrm{SiO}$.

Keywords: optical coherence tomography, silicone oil, pars plana vitrectomy, proliferative vitreoretinopathy, proliferative diabetic retinopathy

\section{Introduction}

Optical coherence tomography (OCT) is a noninvasive technique that provides high-resolution images of the macular layers. ${ }^{1}$ Pars plana vitrectomy (PPV) with silicone oil ( $\mathrm{SiO})$ tamponade has been used for complicated retinal detachment $(\mathrm{RD})$ with proliferative vitreoretinopathy (PVR) and proliferative diabetic retinopathy (PDR). ${ }^{2-4} \mathrm{SiO}$ is subsequently removed before the occurrence of complications, such as dense complicated cataracts, secondary glaucoma, keratopathy, and emulsification..$^{5-9}$ However, other complications such as epiretinal membrane (ERM), macular holes, macular edema, sensory detachment, and thinning of the retinal layers can clinically be easily missed. These complications, if present, can affect visual outcome, and some of them require modification of the surgical maneuver during the removal of $\mathrm{SiO} .{ }^{5-9}$ Few studies have used OCT as a routine tool to assess the macula before the removal of SiO. OCT can be used in $\mathrm{SiO}$-filled eyes to examine the posterior segments when the media are clear. ${ }^{10}$ 
We set out to evaluate the role of preoperative OCT in the detection of macular changes when used routinely before the removal of $\mathrm{SiO}$.

\section{Patients and methodology}

This study was a cross-sectional study performed between July 2011 and September 2014. This study adhered to the Tenets of the Declaration of Helsinki. The Research Ethics Committee, Faculty of Medicine, Ainshams University (FMAUS REC) approved the protocol of this study from the ethical point of view. Written informed patient consent was also obtained.

\section{Inclusion criteria}

1) $\mathrm{PPV}$ and $\mathrm{SiO} 2000$ injection.

2) Different indications including PVR $B$ and $C$, PDR, penetrating trauma, uveitis, recurrent $\mathrm{RD}$, giant retinal tears (GRT), and macular holes.

3) Plan for the removal of $\mathrm{SiO}$ with or without phacoemulsification to be performed 6-12 months after primary surgery.

\section{Exclusion criteria}

1) Media opacity as a cataract or corneal opacity that prevents OCT imaging.

2) $\mathrm{SiO}$ present for $>12$ months.

3) $\mathrm{SiO}$ total emulsification or hemorrhage opacifying the view.

4) $\mathrm{SiO}$-induced glaucoma.

An opthalmological examination including indirect ophthalmoscopy, slit lamp biomicroscopy, and preoperative and postoperative visual acuity was carried out on all eyes. All surgical details were recorded on the patient follow-up chart. Biometry was performed using a Ziess IOLMaster SiO formula.

Examination using OCT (Ziess Cirrus, software version 4.5; Carl Zeiss Meditec AG, Jena, Germany) was performed for the macular area by scanning across a series of six radiating cross-sectional B scans of $6 \mathrm{~mm}$ with the center of each scan placed at the center of the fovea using a fast macula map including central macular thickness. Macular GUBE-5 raster lines were used in the eyes with neurosensory RD and ERM with traction. Macular edema was defined as increased retinal thickness calculated with an OCT algorithm at the central fovea between the inner retinal surface and the retinal pigment epithelium. Patients with significant cataracts underwent microcoaxial phacoemulsification using an Infiniti ${ }^{\circledR}$ machine (Alcon Laboratories, Inc., Fort Worth, TX, USA). Hydrophobic acrylic intraocular lenses with appropriate power were implanted.
All patients had standard three-port sclerotomies in the pars plana, $3.5 \mathrm{~mm}$ from the limbus. SiO was left to flow passively under the effect of infusion fluid pressure. Endoillumination using the halogen light of a CONSTELLATION Vitrectomy Machine ${ }^{\circledR}$ (Alcon Laboratories, Inc.) was used to examine the macular region after the removal of $\mathrm{SiO}$. The macular pathology found in the OCT examination was checked and dealt with intraoperatively. Eyes with significant ERM traction needed peeling after the removal of SiO. Eyes with macular edema needed pharmacotherapy, and eyes with macular RD needed drainage of subretinal fluid. Eyes that needed further tamponade were injected with perfluoropropane (C3F8). All eyes were refracted to achieve the best-corrected visual acuity (BCVA) after 4 weeks. Postoperative measurements of visual acuity $(\log M A R)$ were recorded. Statistical analysis was performed to evaluate OCT findings in correlation with preoperative fundus appearance, surgical findings, and visual outcome.

\section{Statistical analysis}

The following formula was used for sample calculation:

$$
\frac{2([50])^{2} \times 7.9}{(10)^{2}}
$$

An adequate sample should be at least 40 eyes.

Data were collected, coded, revised, and entered into the Statistical Package for Social Science (SPSS) version 20. Qualitative data were presented as number and percentages and compared using the chi-square test. Quantitative data were presented as means, standard deviations, and ranges and compared using an independent $t$-test. Confidence intervals were set to $95 \%$, and the margin of error accepted was $5 \%$. The $P$-value was considered significant at a level of $<0.05$.

\section{Results}

Results included 51 eyes from 48 patients. Of those patients, $20(41.6 \%)$ were females and 28 (58.4\%) were males. Original diagnoses before performing PPV and $\mathrm{SiO}$ are given in Table 1.

Table I Original diagnosis before pars plana vitrectomy (PPV)

\begin{tabular}{lll}
\hline Diagnosis & Number & Percent \\
\hline PVR & 15 & 29.4 \\
PDR & 12 & 23.5 \\
Penetrating trauma & 8 & 15.7 \\
Recurrent RD & 5 & 9.8 \\
Uveitis & 4 & 8 \\
GRT & 4 & 8 \\
Macular hole & 3 & 5.9 \\
\hline
\end{tabular}

Abbreviations: PVR, proliferative vitreoretinopathy; PDR, proliferative diabetic retinopathy; RD, retinal detachment; GRT, giant retinal tear. 
Preoperative OCT examination of the macula showed macular edema in 14 eyes $(27.5 \%)$; this was diabetic macular edema (Figure 1) in seven eyes (13.7\%) and cystoid macular edema (CME) in seven eyes (13.7\%; Figure 2). CME was present in five out of fifteen (33.3\%) of PVR eyes, one of GRT eyes, and one out of four uveitic eyes (25\%). Diabetic macular edema was found seven out of twelve
(58.3\%) of PDR eyes. ERMs were detected by OCT in 21 eyes (41.2\%); this included fine ERM in 13 eyes $(25.5 \%$; Figure 3$)$ and ERM with traction in eight eyes (15.7\%; Figure 4). Neurosensory RD was found in seven eyes (13.7\%; Figure 5), macular thinning was found in seven eyes (13.7\%; Figure 6), and macular holes were found in five eyes (9.8\%; Figure 7). Emulsification of $\mathrm{SiO}$ at the

Doctor: $\quad$ Signal strength: $7 / 10$

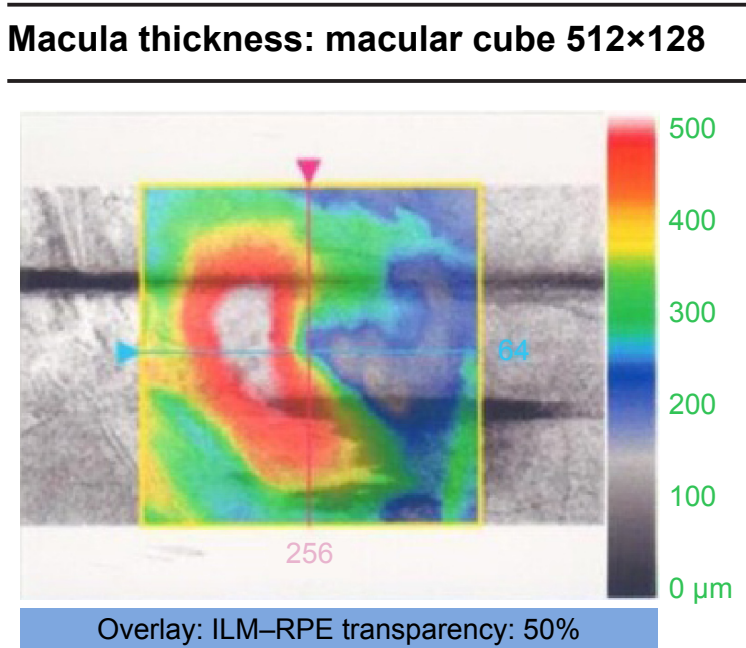

High-definition mode
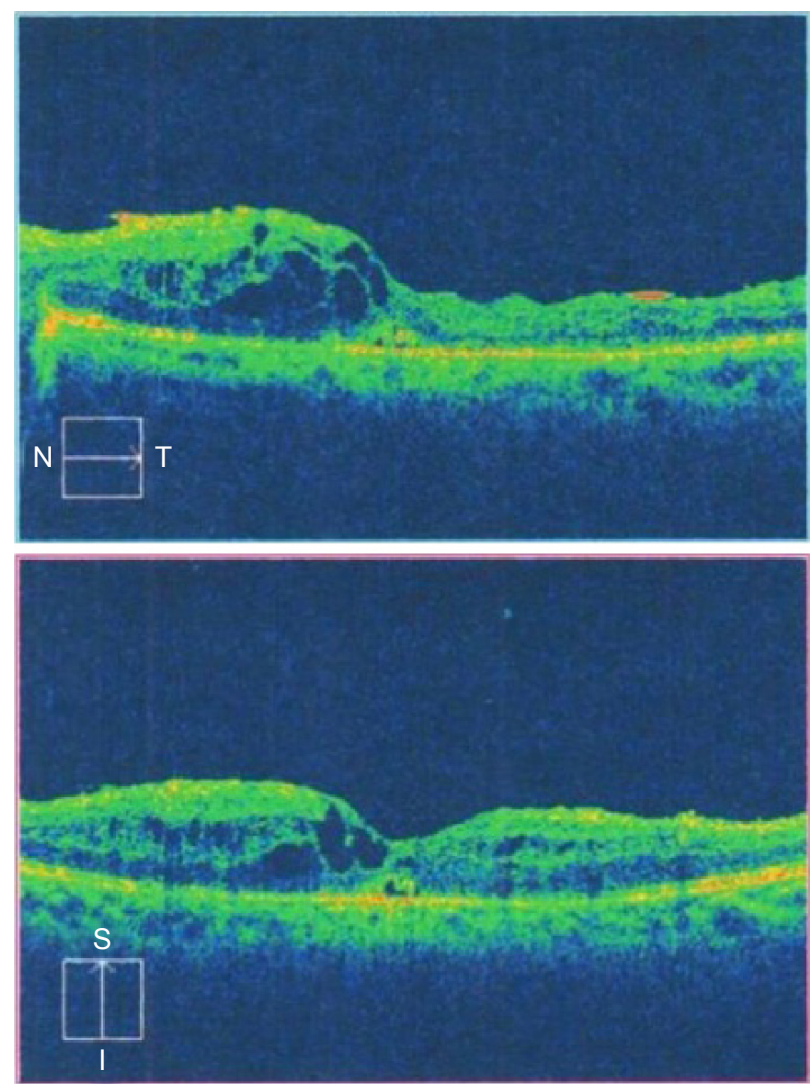

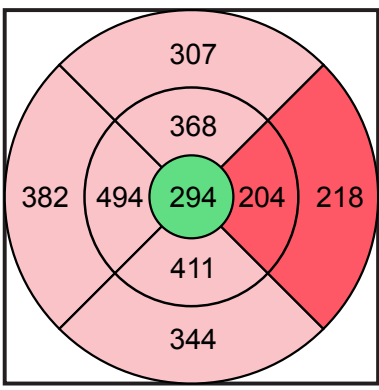

ILM-RPE thickness $(\mu \mathrm{m})$
OD $\bigcirc$ OS

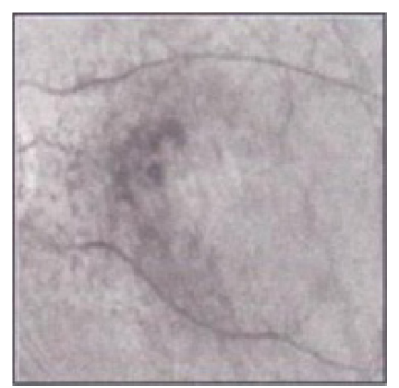

Fovea: 256, 62

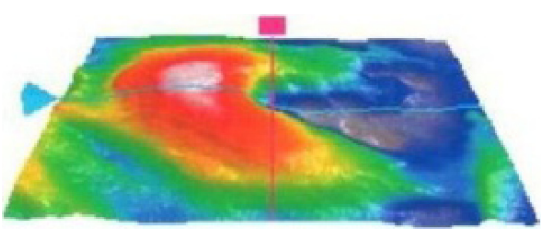

ILM-RPE

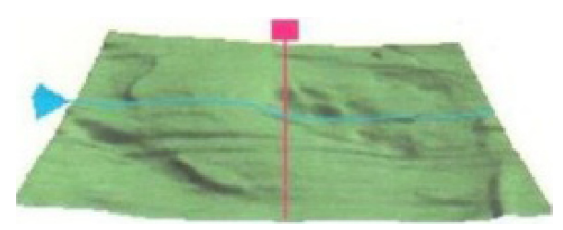

ILM

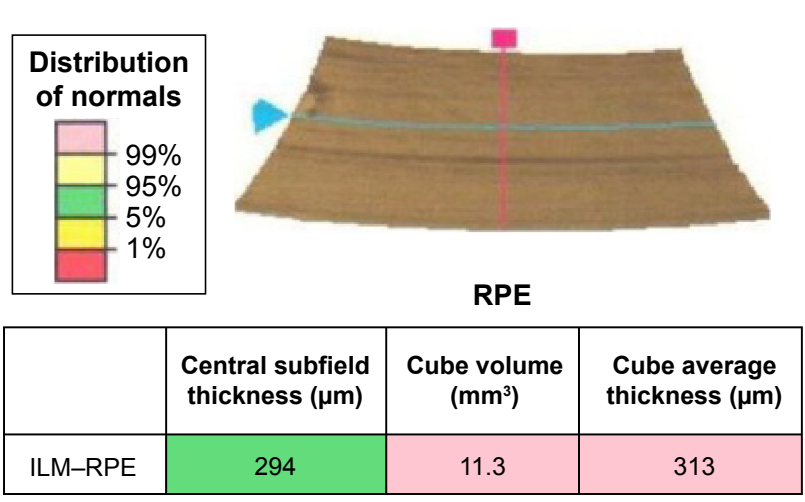

Figure I Diabetic macular edema under SiO.

Abbreviations: SiO, silicone oil; OD, right; OS, left; ILM, internal limiting membrane; RPE, retinal pigmented epithelium; t, temporal; S, superior; I, inferior; N, nasal. 


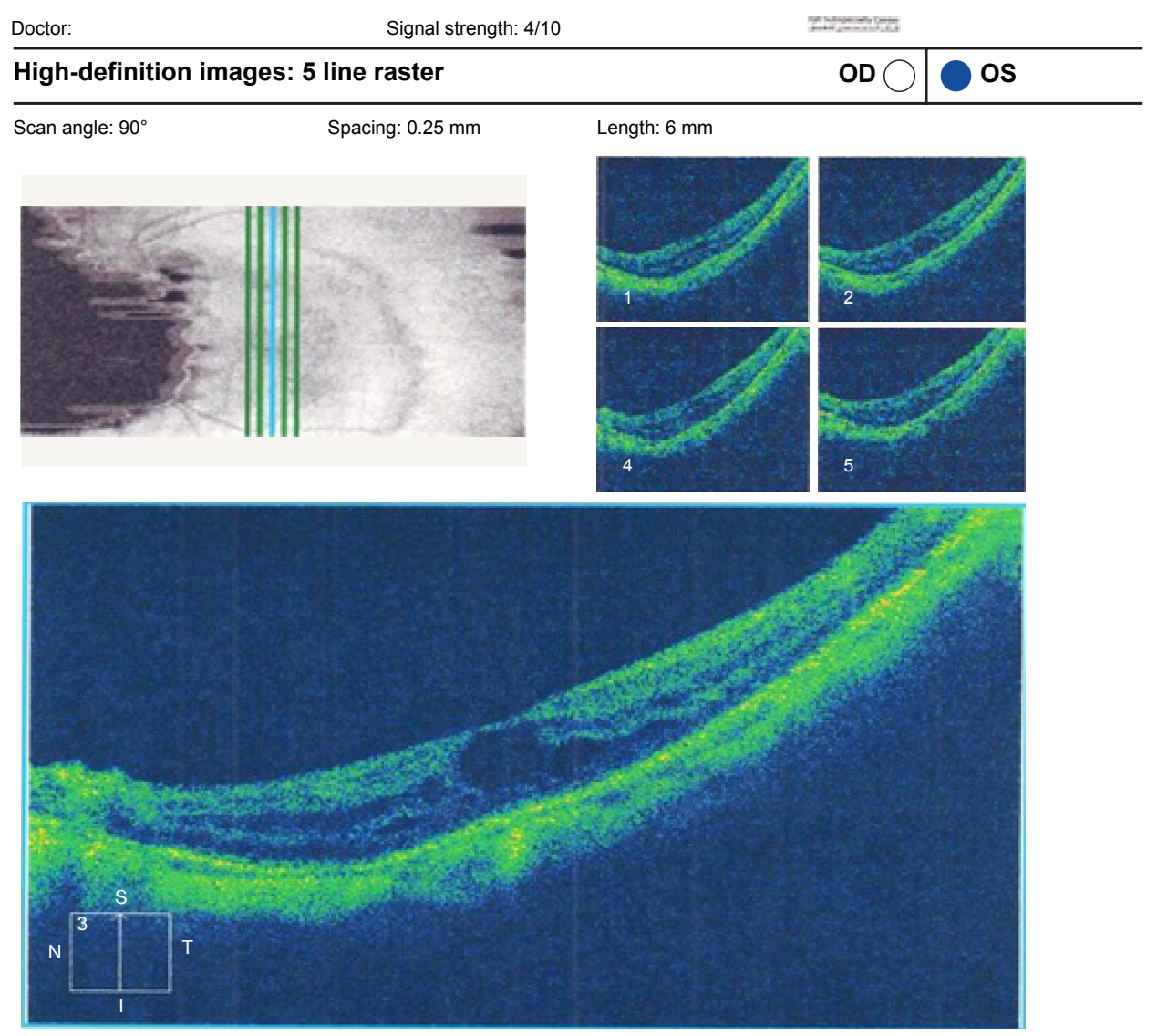

\begin{tabular}{ll|l} 
Doctor: & Signal strength: $3 / 10$ & \\
\hline Macula thickness: macular cube $512 \times 128$ & OD $\bigcirc$ & OS \\
\hline
\end{tabular}

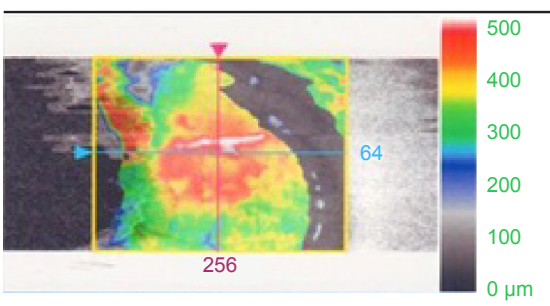

Overlay: ILM-RPE transparency: 50\%

High-definition mode
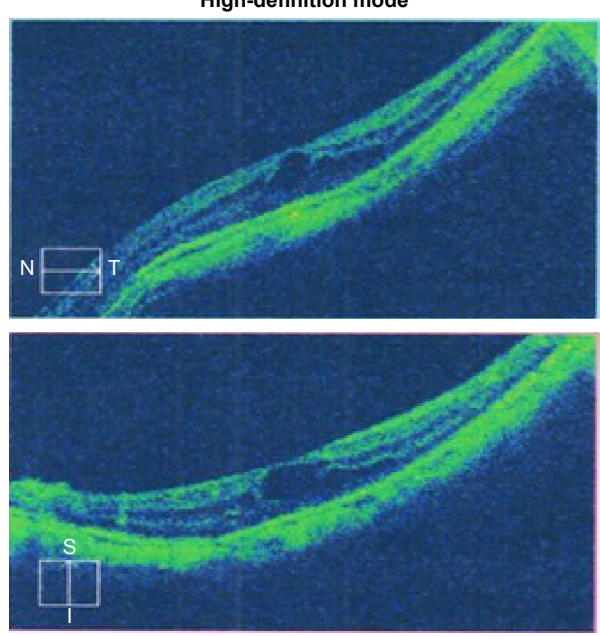

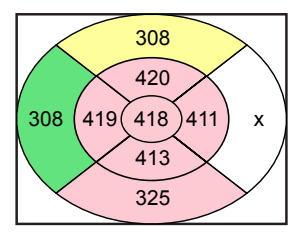

ILM-RPE thickness

$(\mu \mathrm{m})$

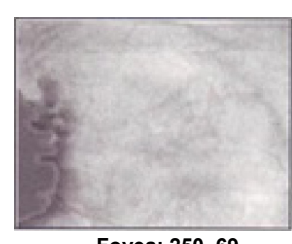

Fovea: 250, 69

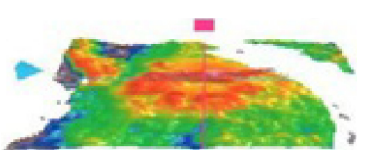

ILM-RPE

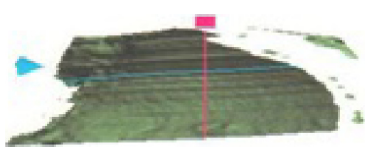

ILM

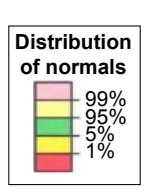

\begin{tabular}{|l|c|c|c|}
\hline & $\begin{array}{c}\text { Central subfield } \\
\text { thickness }(\boldsymbol{\mu m})\end{array}$ & $\begin{array}{c}\text { Cube volume } \\
\left(\mathbf{m m}^{3}\right)\end{array}$ & $\begin{array}{c}\text { Cube average } \\
\text { thickness }(\boldsymbol{\mu m})\end{array}$ \\
\hline ILM-RPE & 418 & 9.0 & 251 \\
\hline
\end{tabular}

Figure 2 (Top) CME under SiO in GRT. (Bottom) CME under SiO in GRT.

Abbreviations: CME, cystoid macular edema; SiO, silicone oil; GRT, giant retinal tear; OD, right; OS, left; ILM, internal limiting membrane; RPE, retinal Pigmented epithelium; t, temporal; S, superior; I, inferior; N, nasal. 

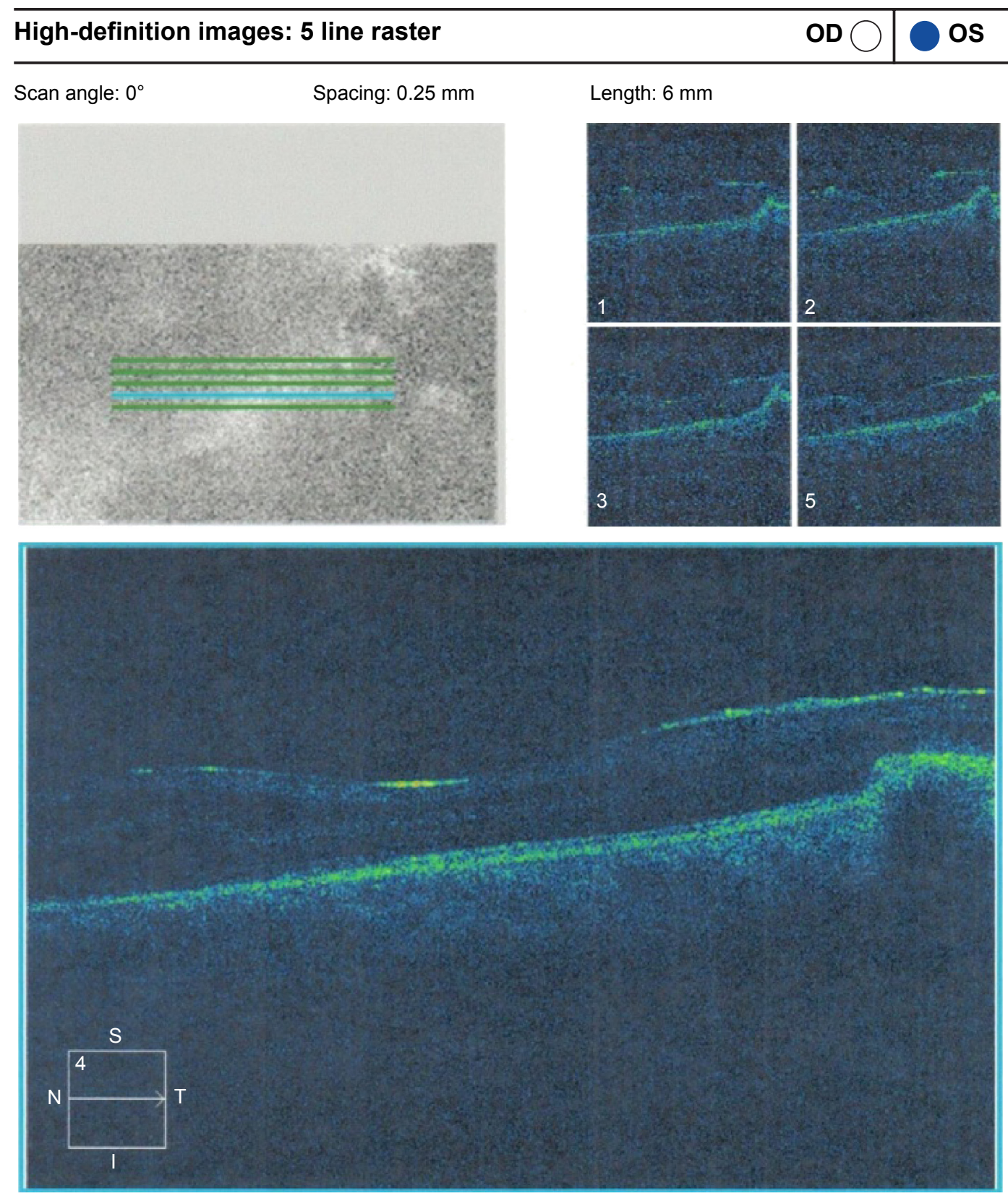

Figure 3 ERM without traction.

Abbreviations: ERM, epiretinal membrane; OD, right; OS, left; t, temporal; S, superior; I, inferior; N, nasal.

macula was detected by OCT in two eyes (4\%; Figure 8 ), and one eye (2\%) had a subretinal band (Figure 9). Overall, abnormal OCT findings were present in 45 eyes $(88.2 \%)$ and normal OCT findings were found in six eyes $(11.8 \%$; Figure 7; Table 2).

Clinically, normal macula were seen in 22 eyes (43\%) before the removal of SiO. Preoperative OCT examination of these eyes with clinically normal macula was normal in only four eyes (18\%).

Table 3 shows the abnormalities detected by preoperative OCT in those eyes with clinically normal macula.
OCT detected macular pathological changes occurred in $88.24 \%$ of all eyes. Clinical fundus examination detected fewer changes $(56.86 \%)$. The difference in the detection ability was highly significant $(P<0.001$; Table 4 ; Figure 10).

Mean $\log$ MAR after the removal of $\mathrm{SiO}$ was $0.35(20 / 45$ Snellen's acuity) in eyes with preoperative normal OCT. It was 1.22 (20/380 Snellen's acuity) in eyes with abnormal OCT before the removal of SiO. The difference was highly significant $(P<0.001$; Table 5; Figure 11).

OCT findings were less than expected from clinical examination in three of 51 eyes (5\%; Figure 12). Surgical 

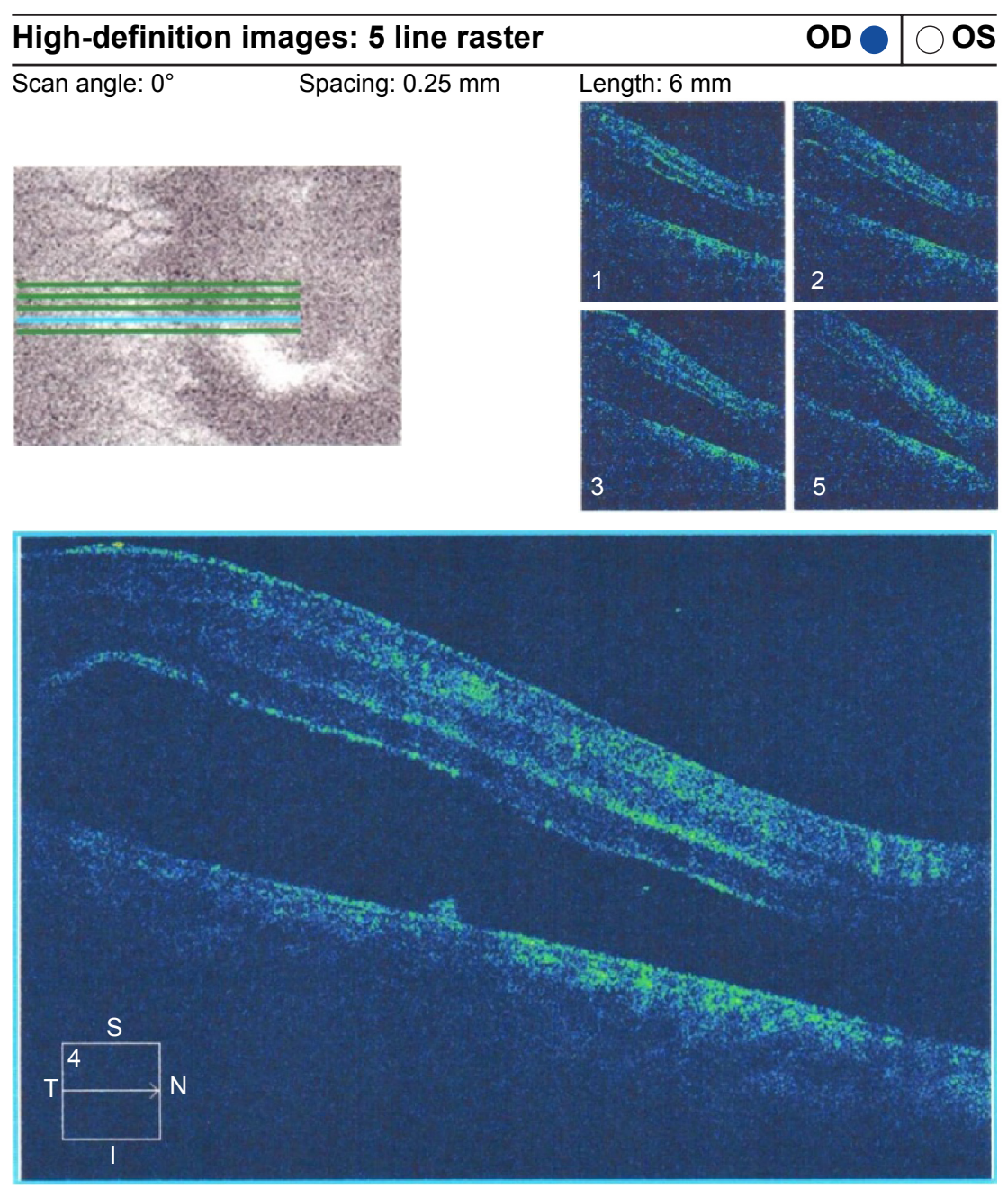

Figure 4 ERM with traction RD.

Abbreviations: ERM, epiretinal membrane; RD, retinal detachment; OD, right; OS, left; t, temporal; S, superior; l, inferior; N, nasal.
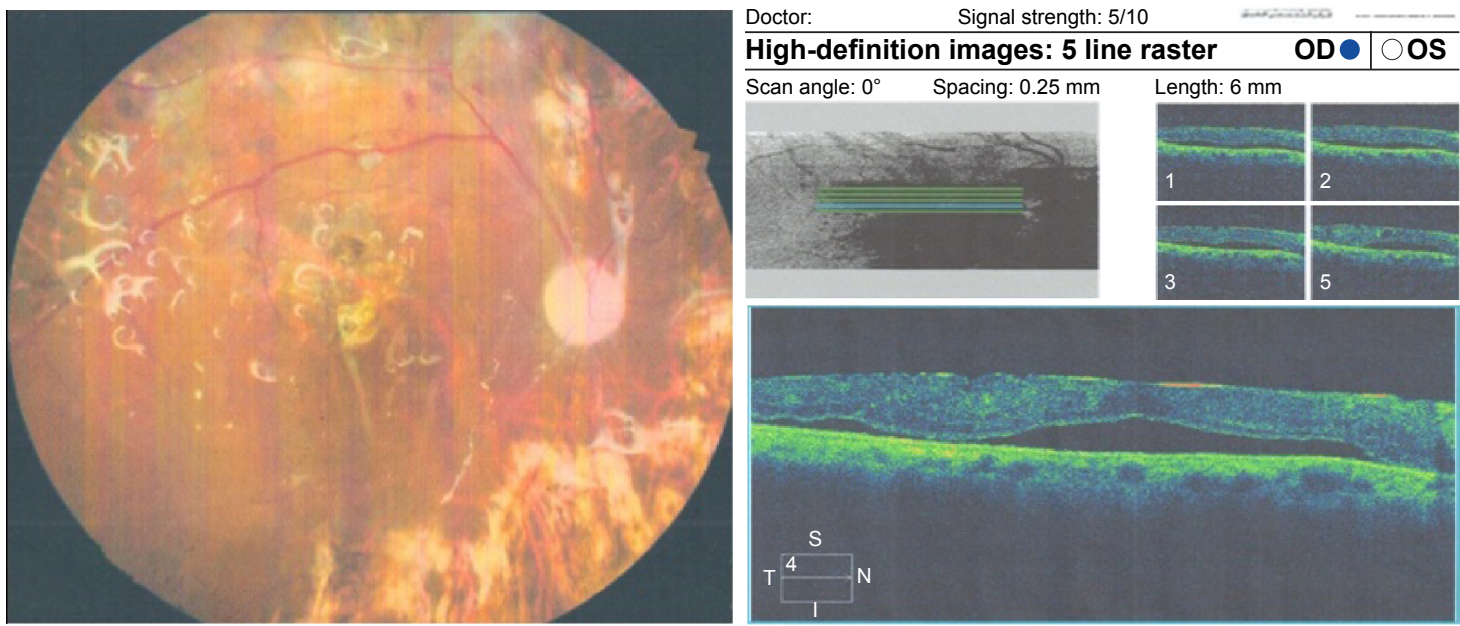

Figure 5 Left fundus photo of a diabetic patient with PPV and SiO and OCT of the same patient with shallow macular detachment.

Notes: (Left) Colored fundus picture from a diabetic patient who underwent PPV with SiO injection. (Right) OCT raster lines of the same patient showing shallow RD and fine ERM.

Abbreviations: PPV, pars plana vitrectomy; SiO, silicone oil; OCT, optical coherence tomography; RD, retinal detachment; ERM, epiretinal membrane; OD, right, OS, left; t, temporal; S, superior; I, inferior; N, nasal. 


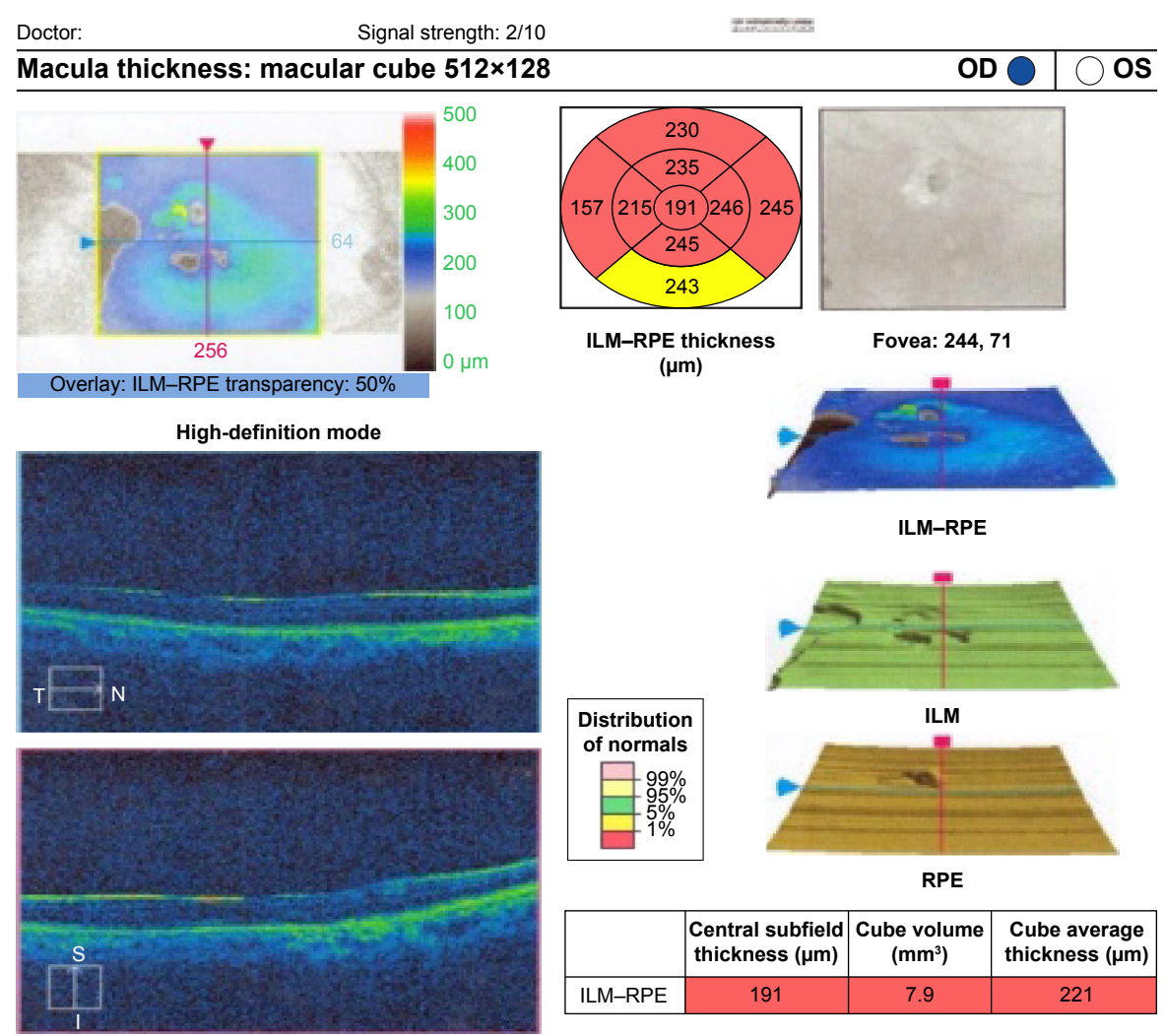

Doctor: Signal strength: 2/10

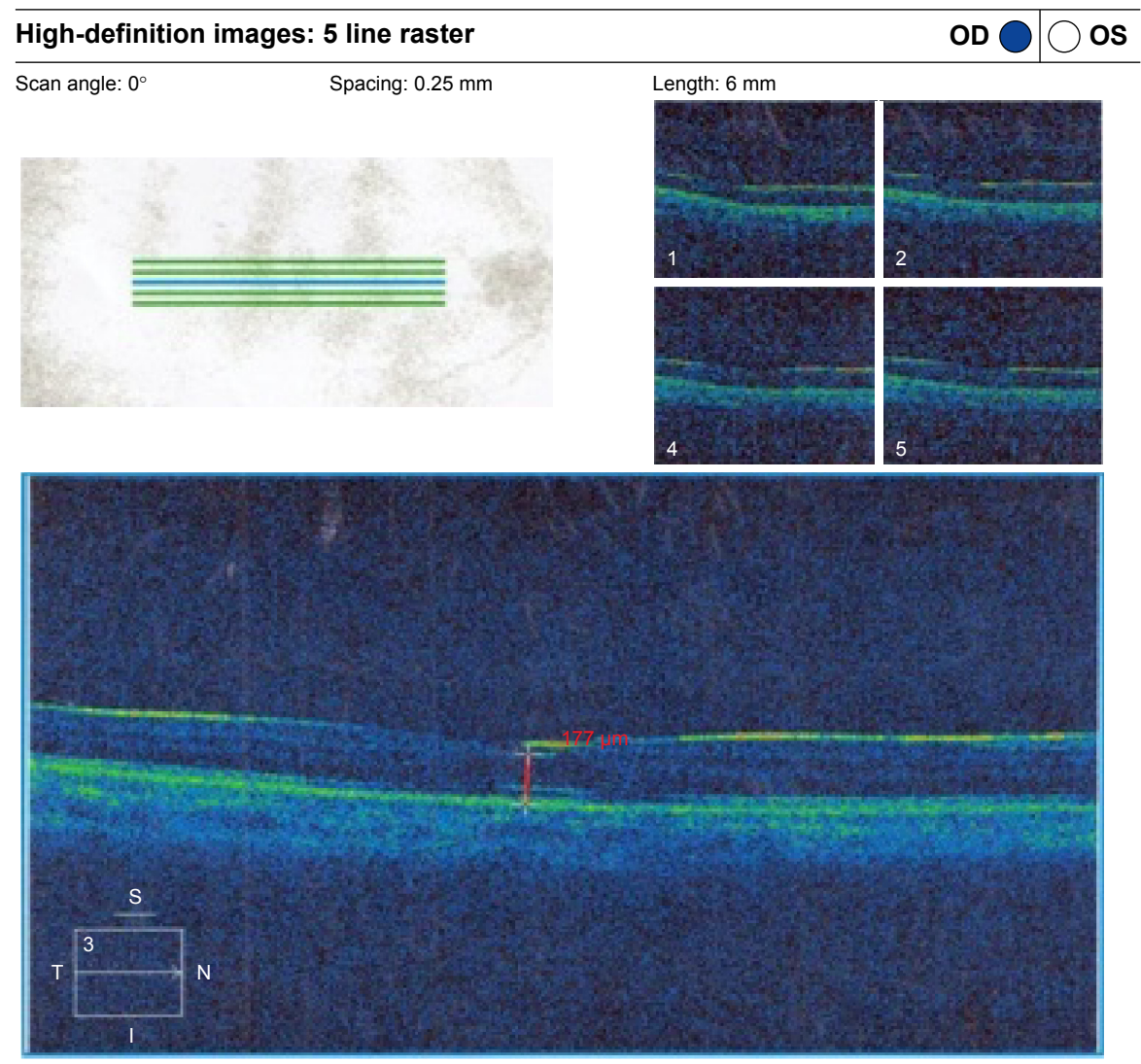

Figure 6 (Top) Patient fast thickness map. (Bottom) Macular thinning in SiO-filled eye with normal fundus raster lines.

Abbreviations: SiO, silicone oil; OD, right; OS, left; t, temporal; S, superior; I, inferior; N, nasal; ILM, internal limiting membrane; RPE, retinal pigmented epithelium. 


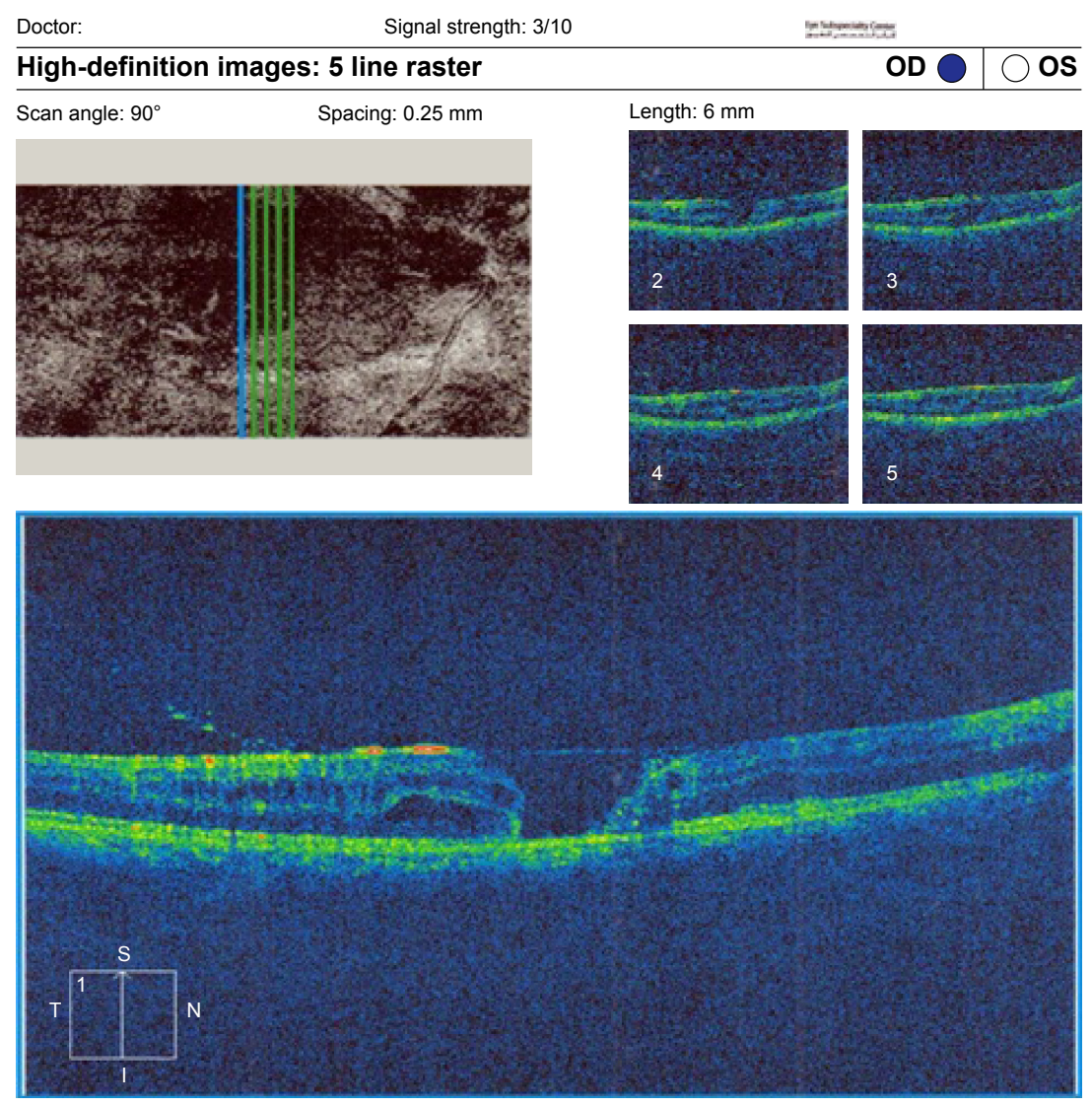

$$
\text { Doctor: Signal strength: 5/10 }
$$
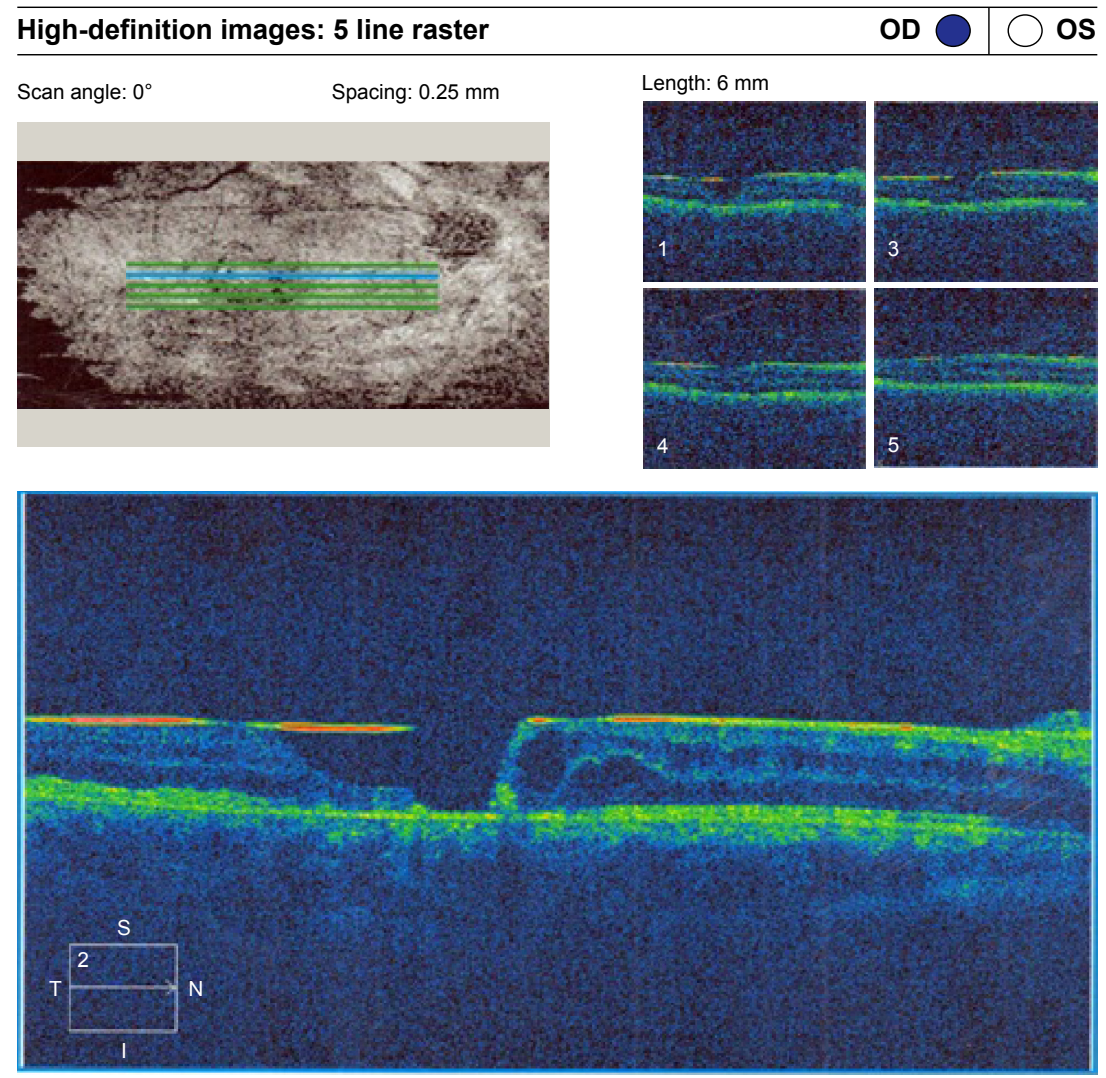

Figure 7 (Top) Macular hole with macular edema and posterior silicone face. (Bottom) Another raster line of the same patient. Abbreviations: OD, right; OS, left; t, temporal; S, superior; I, inferior; N, nasal. 
Doctor:

Signal strength: $5 / 10$

(1)
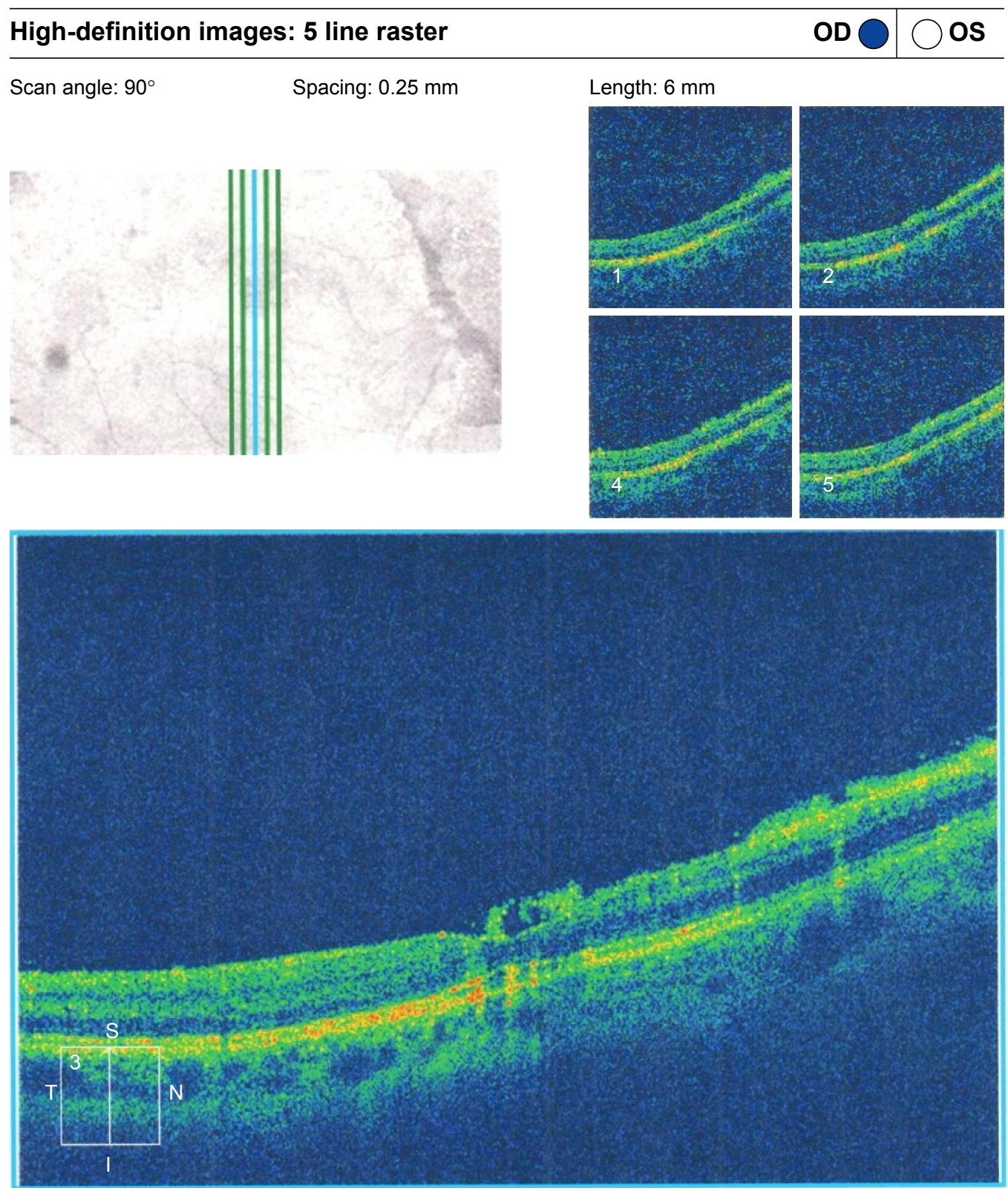

Figure 8 Raster OC with premacular emulsified $\mathrm{SiO}$ in an eye that underwent PPV for recurrent RD.

Abbreviations: OC, optical coherence; SiO, silicone oil; PPV, pars plana vitrectomy; RD, retinal detachment; OD, right; OS, left; t, temporal; S, superior; I, inferior; N, nasal.

findings during the removal of $\mathrm{SiO}$ corresponded to preoperative OCT examination in 37 of 51 eyes $(72.5 \%)$. Details of the surgical findings corresponding to preoperative OCT in each subgroup are described in Table 6.

Surgical plans during the removal of $\mathrm{SiO}$ were changed based on preoperative OCT findings in 38 of 51 eyes (74.5\%). Details of the changes in surgical plans for PVR and PDR eyes are described in Table 7.

In trauma, GRT, macular holes, and recurrent detachment, the surgical plan was changed in $100 \%$ of eyes with abnormal OCT results.

\section{Discussion}

OCT operates through a mechanism similar to ultrasonography by replacing ultrasound waves with infrared waves. ${ }^{1}$ It provides higher resolution images than ultrasonography. This enables OCT to assess $\mathrm{SiO}$ and detailed macular pathology in eyes with clear media. ${ }^{11}$ We included eyes that needed SiO tamponade for 6-12 months because of their complicated RD. Our concern was the ability of OCT to detect macular pathological changes in the presence of $\mathrm{SiO}$ and its correlation to clinical and surgical findings. Maia et al ${ }^{12}$ studied the changes in silicone-filled eyes. They included fewer eyes 

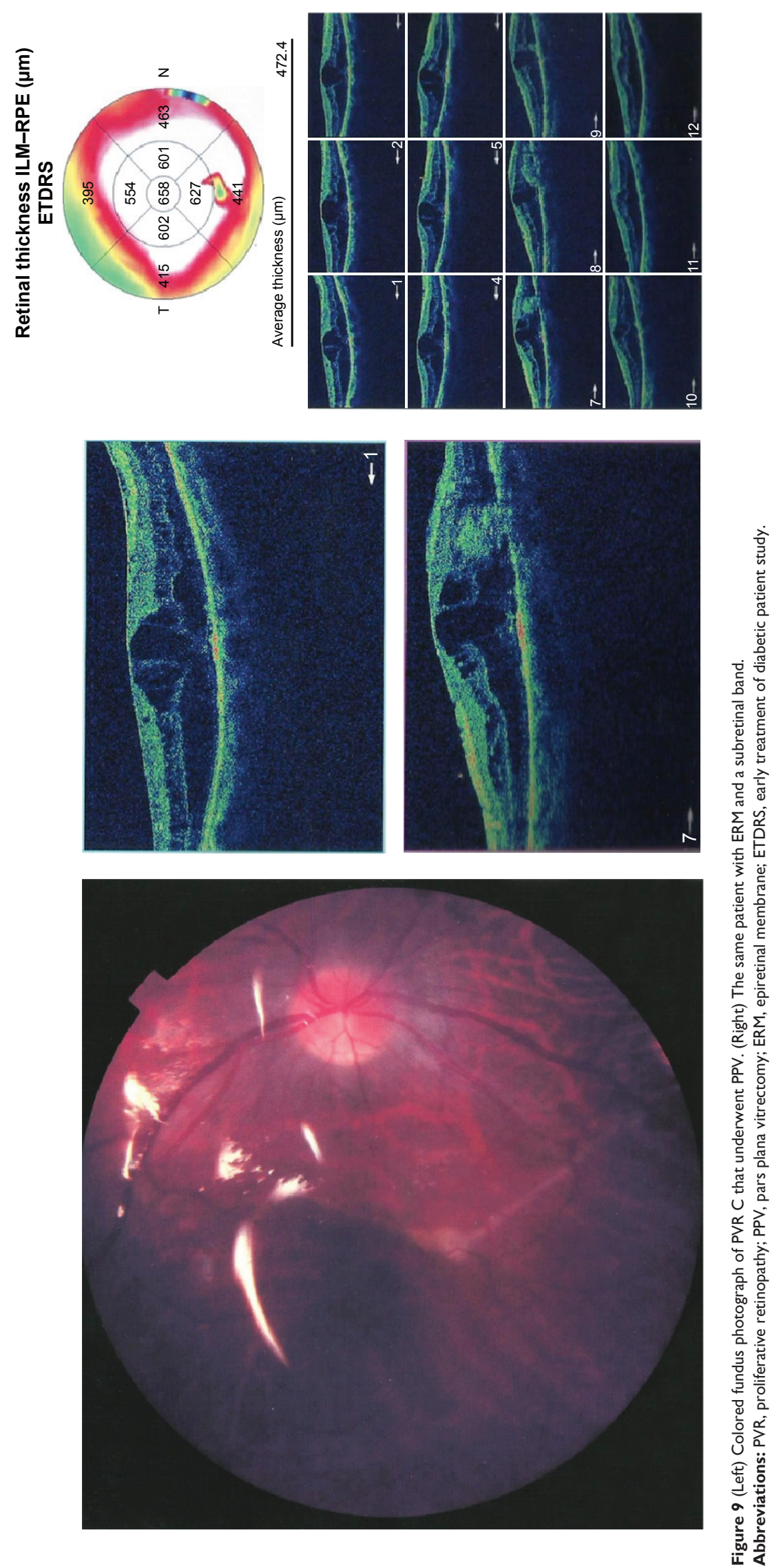
Table 2 OCT findings before the removal of SiO

\begin{tabular}{lll}
\hline OCT findings & Number & Percent \\
\hline Macular edema & 14 & 27.5 \\
DME & 7 & 13.7 \\
CME & 7 & 13.7 \\
ERM & 21 & 41.2 \\
Fine & 13 & 25.5 \\
Traction & 8 & 15.7 \\
Neurosensory retinal detachment & 7 & 13.5 \\
Macular thinning & 7 & 13.5 \\
Macular hole & 5 & 13.5 \\
Subretinal band & 1 & 9.8 \\
Normal & 6 & 2 \\
\hline
\end{tabular}

Abbreviations: $\mathrm{OCT}$, optical coherence tomography; SiO, silicone oil; DME, diabetic macular edema; CME, cystoid macular edema; ERM, epiretinal membrane.

Table 3 Preoperative OCT abnormalities in eyes with clinically normal macula

\begin{tabular}{lll}
\hline Findings & Number & Percent \\
\hline Macular edema & 5 & 22.7 \\
Neurosensory retinal detachment & 3 & 13.6 \\
Macular thinning & 3 & 13.6 \\
Fine ERM & 2 & 9 \\
Emulsified silicon & $\mathrm{I}$ & 4.5 \\
Normal OCT & 4 & 18 \\
\hline
\end{tabular}

Abbreviations: OCT, optical coherence tomography; ERM, epiretinal membrane.

Table 4 Comparison between preoperative fundus examination and detection of OCT abnormalities

\begin{tabular}{|c|c|c|c|c|c|c|}
\hline & \multicolumn{2}{|l|}{ OCT } & \multicolumn{2}{|c|}{ Clinical fundus } & \multicolumn{2}{|c|}{$\begin{array}{l}\text { Chi-square } \\
\text { test }\end{array}$} \\
\hline & Number & Percent & Number & Percent & $x^{2}$ & P-value \\
\hline Normal & 6 & 11.76 & 22 & 43.14 & 11.076 & $<0.001$ \\
\hline Abnormal & 45 & 88.24 & 29 & 56.66 & & \\
\hline
\end{tabular}

Abbreviation: OCT, optical coherence tomography.

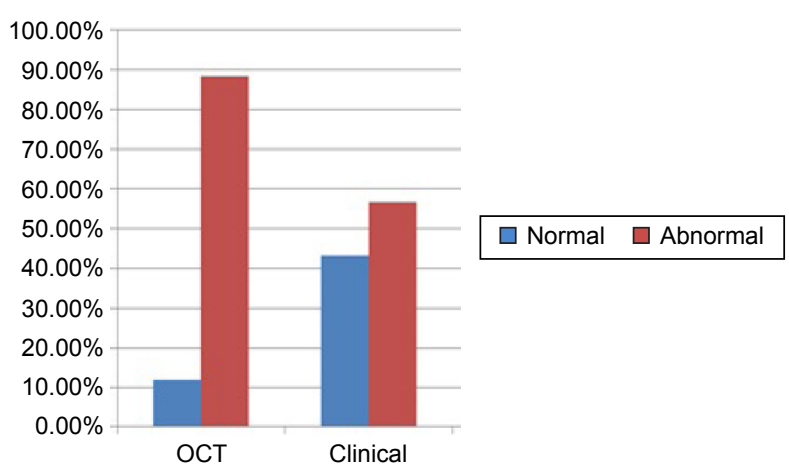

Figure $10 \mathrm{OCT}$ detects more abnormalities in the macula than clinical examination. Abbreviation: OCT, optical coherence tomography.
Table 5 Comparison of postoperative mean logMAR in eyes with preoperative normal and abnormal OCT

\begin{tabular}{llllll}
\hline & \multicolumn{2}{l}{ LogMAR } & & \multicolumn{2}{l}{ Independent $\boldsymbol{t}$-test } \\
\cline { 2 - 3 } \cline { 6 - 6 } & Mean & SD & & $\boldsymbol{t}$ & P-value \\
\hline Normal & 0.35 & 0.22 & & 5.866 & $<0.001$ \\
Abnormal & 1.28 & 0.37 & & \\
\hline
\end{tabular}

Abbreviations: OCT, optical coherence tomography; SD, standard deviation.

$(\mathrm{n}=28)$, and details of some examples of the cases were described. However, the study concluded that systematic use of OCT was useful in recognizing retinal changes.

Avitabile et a ${ }^{13}$ found that the presence of $\mathrm{SiO}$ does not affect measurements of foveal thickness during OCT. They excluded eyes with macular holes and ERM and performed OCT only 3 months after $\mathrm{SiO}$ injection. They did not report the percentage of each macular abnormality. We compared the abnormal findings in the macula detected during clinical examination of the fundus to those detected by preoperative OCT. Numbers of pathological macular changes detected by OCT were highly significantly greater than those detected by a clinical fundus examination. No previous studies had compared preoperative OCT findings to clinical findings. Some of the findings detected by preoperative OCT examination could not be detected during surgery for the removal of $\mathrm{SiO}$. This included macular edema in $27.5 \%$ of all eyes and macular atrophy in $13.5 \%$ of all eyes. Macular edema was the most common abnormality in all eyes $(27.5 \%)$ and in eyes with clinically normal macula under $\mathrm{SiO}$ removal (22.7\%). This means there is difficulty in clinical detection of macular edema in the presence of SiO. In PVR eyes 33\% had CME and in PDR eyes 58.3\% had DME. Theses findings raise the question about the value of pharmacotherapy under $\mathrm{SiO}$. In our study we used pharmacotherapy in all eyes at the time of $\mathrm{SiO}$ removal.

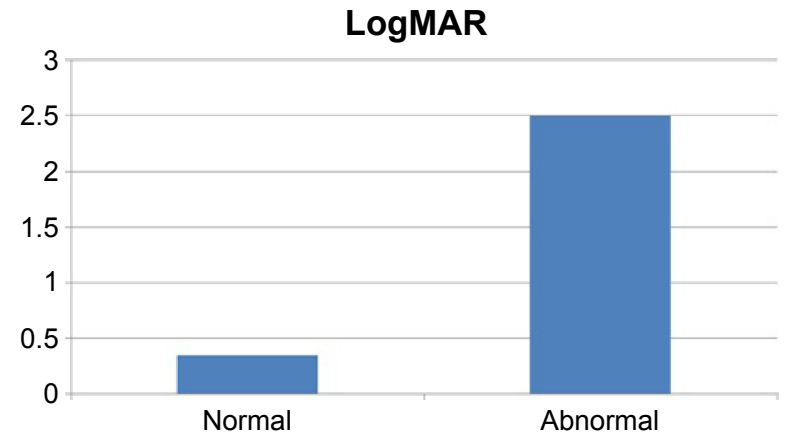

Figure I I Mean logMAR after the removal of SiO in eyes with normal and abnormal preoperative OCT.

Abbreviations: $\mathrm{SiO}$, silicone oil; OCT, optical coherence tomography. 

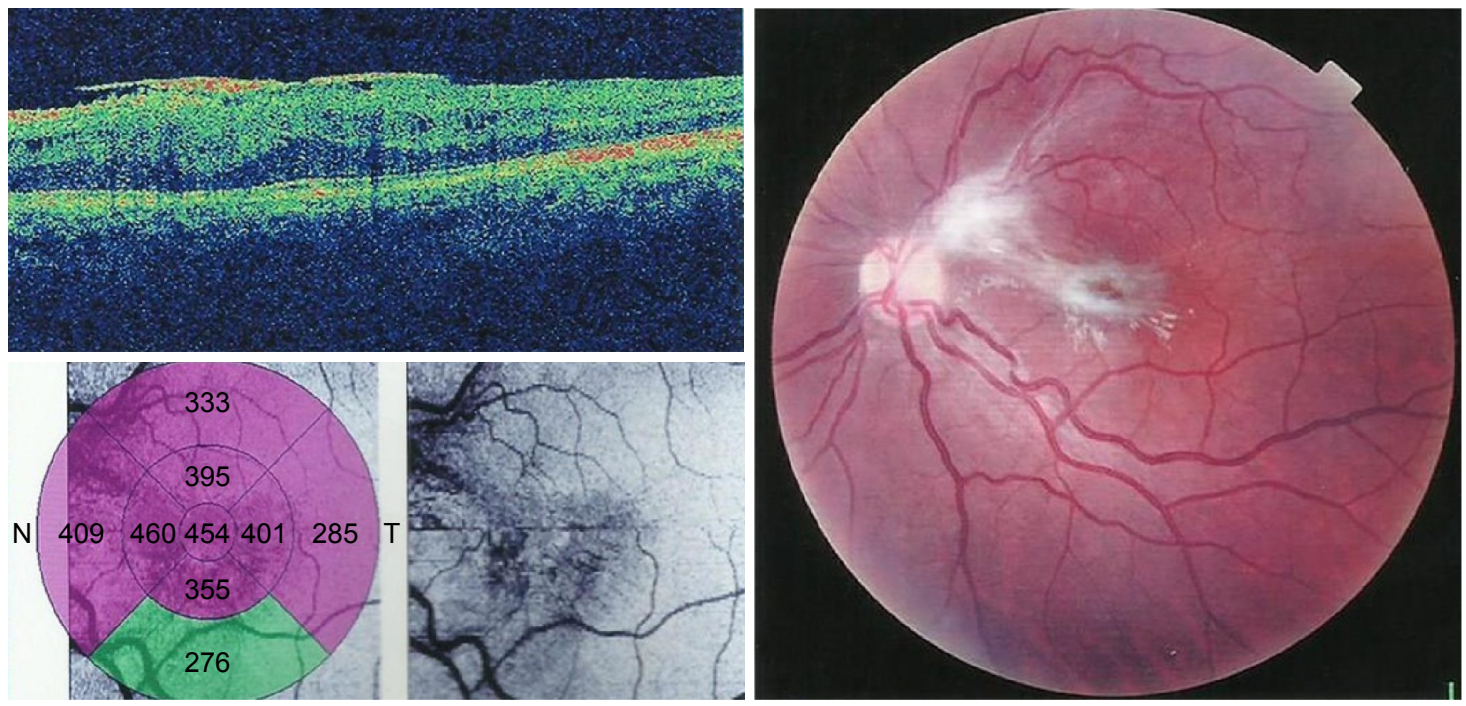

Figure 12 (Left) OCT of a patient with ERM with no tangential traction. (Right) Colored fundus photograph of the same patient with PVR filled with SiO with ERM with tangential traction.

Abbreviations: OCT, optical coherence tomography; ERM, epiretinal membrane; PVR, proliferative retinopathy; SiO, silicone oil.

We found that OCT examination before the removal of $\mathrm{SiO}$ helped to predict visual outcome. We found a highly significant difference in visual outcome in eyes with normal OCT compared with eyes with abnormal OCT before the removal of $\mathrm{SiO}(P<0.001)$. The difference in the visual outcome is explained by the fact that findings detected by OCT affect postoperative visual prognoses. Eyes with normal preoperative OCT had a better postoperative visual outcome. Accordingly, OCT examination can partially explain visual loss not related to cataractogenesis-associated SiO. Avitable et a $1^{13}$ similarly found that postoperative BCVA was significantly correlated to increased and decreased foveal thickness as assessed by OCT, compared to eyes with normal thickness. However, they measured BCVA in the presence of $\mathrm{SiO}$, so it could have been affected by cataract or glaucoma. They only correlated BCVA to thickness, while

Table 6 Correspondence of intraoperative findings during the removal of $\mathrm{SiO}$ to preoperative OCT findings

\begin{tabular}{lll}
\hline & \multicolumn{2}{l}{$\begin{array}{l}\text { Surgical findings } \\
\text { corresponding to OCT }\end{array}$} \\
\cline { 2 - 3 } & Number & Percent \\
\hline PVR & $15 / 15$ & 100 \\
PDR & $5 / 12$ & 41.6 \\
Trauma & $7 / 15$ & 87.5 \\
GRT & $2 / 4$ & 50 \\
Macular hole & $2 / 3$ & 66.6 \\
Recurrent detachment & $3 / 5$ & 60 \\
Uveitis & $3 / 4$ & 75 \\
Total & $37 / 51$ & 72.5 \\
\hline
\end{tabular}

Abbreviations: SiO, silicone oil; OCT, optical coherence tomography; PVR, proliferative vitreoretinopathy; PDR, proliferative diabetic retinopathy; GRT, giant retinal tear. we correlated BCVA to all OCT abnormalities. We noted that intraoperative findings during the removal of $\mathrm{SiO}$ were identical to preoperative OCT examination in $72.5 \%$ of all eyes. Surgical plans were changed from simple removal of $\mathrm{SiO}$ to the addition of other steps in $74.5 \%$ of all eyes according to preoperative OCT examination.

In this study, OCT identified treatable macular pathology in most of the eyes. These included macular edema treated by pharmacotherapy (Figure 13) in 13.5\% and macular sensory neural detachment in $2 \%$. Accordingly, implementation of OCT may help in making earlier decisions for the removal of $\mathrm{SiO}$ to manage underlying macular pathologies for the prevention of visual loss. Macular thinning was present in $13.5 \%$ of the eyes. This may be induced by affection of macular microcirculation due to $\mathrm{SiO}$ that was reported by a laser scanning study. ${ }^{14}$ Three eyes (6\%) had highly elevated macula by OCT. We changed biometry according to the amount of subretinal fluid. In PVR eyes, 100\% had surgical findings corresponding to OCT and the surgical decision was changed in $73 \%$. Findings were related to PVR in $60 \%$ of the eyes (ERM in $40 \%$ and macular RD in 20\%).

Martinez-Castillo et al ${ }^{15}$ reported ERM in $10 \%$ of the PVR eyes. This was different from our prevalence because this

Table 7 Surgical plan changes during the removal of SiO in PVR and PDR eyes based on preoperative OCT findings

\begin{tabular}{lllll}
\hline & Number & Percent & ERM dissection & Pharmacotherapy \\
\hline PVR & II/I5 & 73.3 & $33.3 \%$ & $40 \%$ \\
PDR & $9 / 12$ & 75 & $25 \%$ & $50 \%$ \\
\hline
\end{tabular}

Abbreviations: SiO, silicone oil; PVR, proliferative vitreoretinopathy; PDR, proliferative diabetic retinopathy; OCT, optical coherence tomography; ERM, epiretinal membrane. 


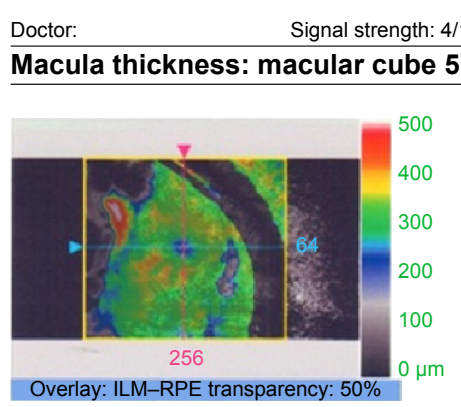

High-definition mode
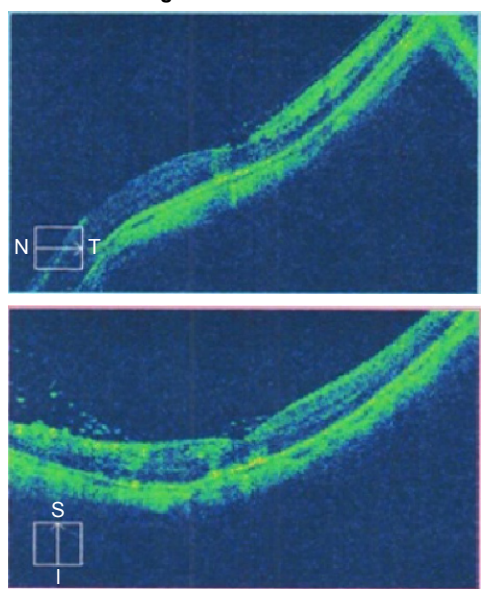

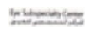
OD $\bigcirc \bigcirc \mathrm{OS}$

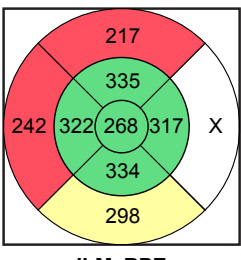

ILM-RPE thickness $(\mu \mathrm{m})$

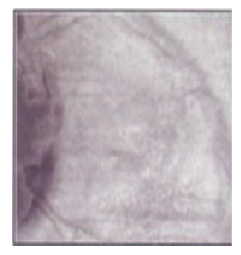

Fovea: 243, 65

튼

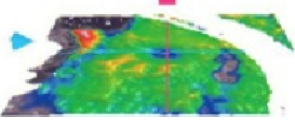

ILM-RPE

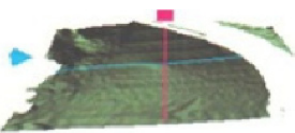

ILM

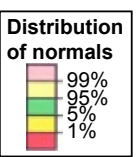

\begin{tabular}{|l|c|c|c|}
\hline & $\begin{array}{c}\text { Central subfield } \\
\text { thickness }(\boldsymbol{\mu m})\end{array}$ & $\begin{array}{c}\text { Cube volume } \\
\left(\mathbf{m m}^{\mathbf{3}}\right)\end{array}$ & $\begin{array}{c}\text { Cube average } \\
\text { thickness }(\boldsymbol{\mu m})\end{array}$ \\
\hline ILM-RPE & 268 & 7.4 & 2.05 \\
\hline
\end{tabular}

High-definition images: 5 line raster OD $\bigcirc \quad$ OS

Scan angle: $80^{\circ}$ Spacing: $0.25 \mathrm{~mm}$ Length: $6 \mathrm{~mm}$
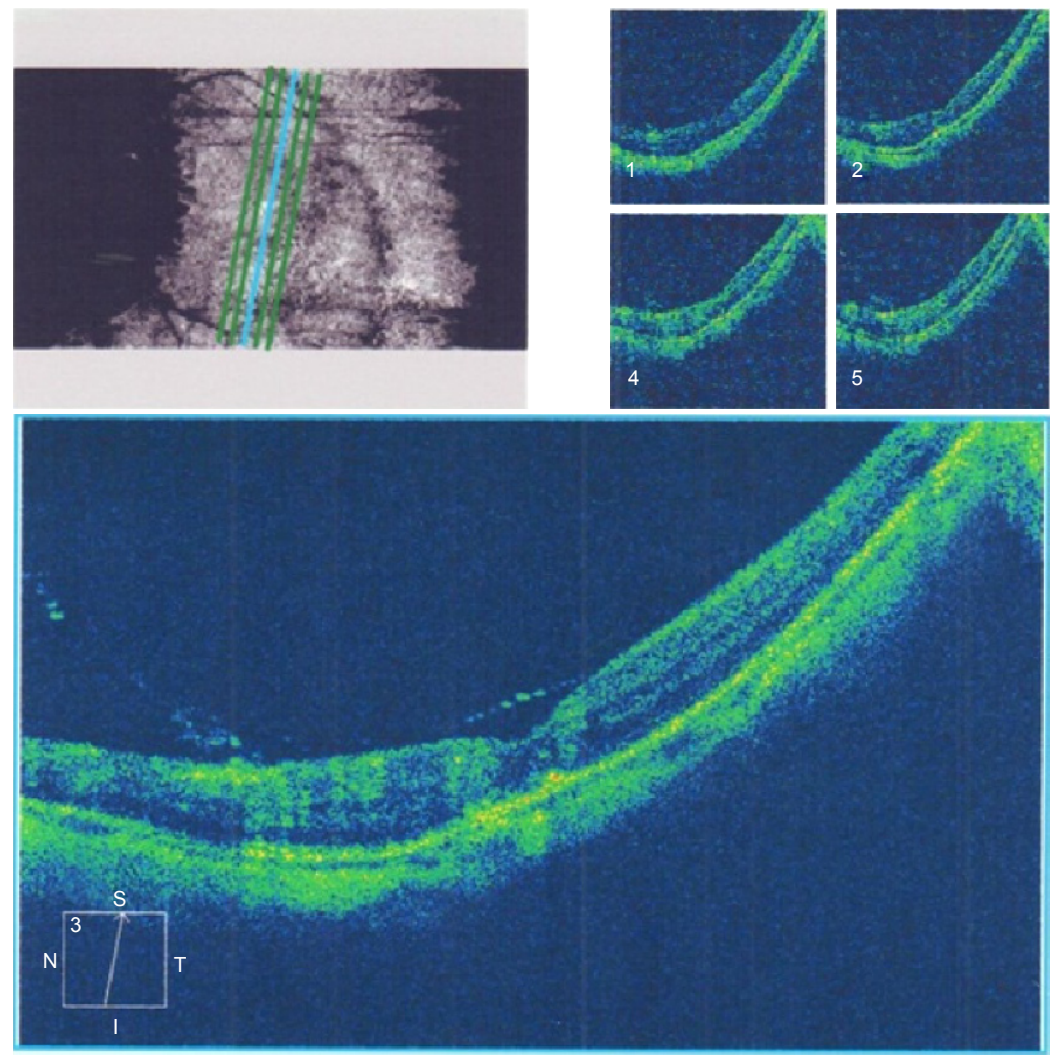

Figure 13 (Top) Fast thickness map improvement of the patient with GRT after pharmacotherapy treatment of CME. (Bottom) Raster line of the same patient. Abbreviations: GRT, giant retinal tear; CME, cystoid macular edema; OD, right; OS, left; t, temporal; S, superior; I, inferior; N, nasal; ILM, internal limiting membrane. 
study was dependent on a fundus examination for detection of ERM and used OCT only to confirm clinical diagnosis of ERM. It also reported only eyes that needed surgical intervention to remove ERM; $15 \%$ of the eyes in our study required surgical removal. In recurrent $\mathrm{RD}$ eyes, $60 \%$ had surgical findings corresponding to OCT. This means that the attachment of the retina and $\mathrm{SiO}$ injection did not stop the process of PVR. In PDR, $41 \%$ of the eyes had surgical findings corresponding to OCT, while in $75 \%$ of the eyes, there was modification of the surgical plan including pharmacotherapy. This disparity occurred because macular edema is not detected during surgery. ERM was removed in $15 \%$ of the eyes.

Messmer et $\mathrm{al}^{16}$ reported the recurrence of ERMs as being significantly associated with poor vision following PPV for PDR and SiO injection. This study specifically focused on eyes with tractional RD. In eyes with penetrating trauma, 62\% had ERM and 37\% had RD. This was similar to the incidence of RD after PPV (41\%) reported in a study for penetrating trauma for intraocular foreign bodies. ${ }^{22}$ The latter study did not report any cases of postoperative ERM. This is explained by our detection using OCT, while the comparative study ${ }^{17}$ did not use OCT. In GRT, 66\% had surgical findings corresponding to OCT and related to the original disease. In uveitic eyes, OCT detected ERM in 75\% and $\mathrm{CME}$ in $50 \%$.

Another study ${ }^{18}$ reported postvitrectomy CME in $11 \%$ and $\mathrm{RD}$ in $7 \%$ of the eyes. ${ }^{18}$ They included a greater number of eyes $(n=28)$. They did not report ERM in any eye. Again, they did not use OCT as a postoperative examination tool. Another study ${ }^{19}$ reported $13.7 \% \mathrm{RD}$ and CME in uveitic eyes. They also included more eyes $(n=51)$ but did not use OCT to examine the macula postoperatively. This may explain the underestimation of ERM and CME in both studies.

\section{Conclusion}

We suggest that performing noncontact OCT before the removal of $\mathrm{SiO}$ is important. It helps to predict visual outcome, which we found was related to cataract density and macular pathologies detected by OCT. It helps to change the surgical plan of the removal of $\mathrm{SiO}$ to manage treatable macular pathologies. It also helps to detect macular edema and thinning that could not be detected intraoperatively. This procedure should be performed routinely before the removal of $\mathrm{SiO}$ whenever the media allow. We recommend the removal of $\mathrm{SiO}$ earlier whenever possible before the development of dense cataracts that prevent OCT performance as a baseline care.

\section{Limitations and flaws to our study}

1) There was a wide spectrum of diagnoses before the use of an $\mathrm{SiO}$ tamponade, including PVR, PDR, recurrent RD, trauma, uveitis, and GRT. We concentrated on abnormalities under $\mathrm{SiO}$ rather than on the primary diagnosis.

2) A small number of eyes were studied in the uveitis and GRT groups.

\section{Author contributions}

MAR participated in the conception and design of the study, intervention, data collection and statistical analysis, manuscript drafting and revising, and editing and approval of the final manuscript. AAM participated in conception and design, data collection, editing and approval of the final manuscript. AIA participated in the data collection, statistical analyses, drafting the manuscript, and editing and approval of the final manuscript. All authors read and approved the final manuscript.

\section{Disclosure}

The authors report that they have no conflicts of interest in this work.

\section{References}

1. Huang D, Swanson EA, Lin CP, et al. Optical coherence tomography. Science. 1991;254:1178-1181.

2. Cibis PA, Becker B, Okun E, Cowan S. The use of liquid silicone in retinal detachment surgery. Arch Ophthalmol. 1962;681:590-599.

3. Scott JD. The treatment of massive vitreous traction by the separation of pre-retinal membranes using liquid silicone oil. Mod Probl Ophthalmol. $1975 ; 15: 285-290$

4. Watzke RC. Silicone retinopiesis for retinal detachment: along-term clinical evaluation. Arch Ophthalmol. 1967;77:185-196.

5. Cockerham WD, Schepens CL, Freeman HM. Silicone injection in retinal detachment. Arch Ophthalmol. 1970;83:704-712.

6. Barr CC, Lai MY, Lean JS, et al. Postoperative intraocular pressure abnormalities in the Silicone Study: Silicone Study report 4. Ophthalmology. 1993;100:1629-1635.

7. Hutton WL, Azen SP, Blumenkranz MS, et al. The effects of silicone oil removal: Silicone Study report 6. Arch Ophthalmol. 1994;112: 778-785.

8. Federman JL, Schubert HD. Complications associated with the use of silicone oil in 150 eyes after retina-vitreous surgery. Ophthalmology. 1988;95:870-876.

9. Ober RR, Blanks JC, Ogden TE, Pickford M, Minckler DS, Ryan SJ. Experimental retinal tolerance to liquid silicone. Retina. 1983;3: $77-85$.

10. Mastropasqua L, Carpineto P, Ciancaglini M, Falconio G, Harris A. Reproducibility of nerve fiber layer thickness measurements using optical coherence tomography in silicone oil-filled eyes. Ophthalmologica. 2001;215(2):91-96.

11. Satchi K, Patel CK. Posterior chamber compartments demonstrated by optical coherence tomography, in silicone-filled eyes, following macular hole surgery. Clin Experiment Ophthalmol. 2005;33:619-622.

12. Maia OO Jr, Takahashi WY, Nakashima Y, Primiano Júnior HP, Takahashi BS, Nakashima AF. Optical coherence tomography macular study on eyes filled with silicone oil. Arq Bras Oftalmol. 2007;70(2): 281-285. 
13. Avitabile T, Bonfiglio V, Sanfilippo M, Torrisi B, Reibaldi A. Correlation of optical coherence tomography pattern and visual recovery after vitrectomy with silicone oil for retinal detachment. Retina. 2006;26(8):917-921.

14. Kubicka-Trzaska A, Kobylarz J, Romanowska-Dixon B. Macular microcirculation blood flow after pars plana vitrectomy with silicone oil tamponade. Klin Oczna. 2011;113(4-6):146-148.

15. Martinez-Castillo V, Boixedara A, Distefano L, Zapata M, GarciaArumi J. Epiretinal membrane after pars plana vitrectomy for primary pseudophakic or aphakic rhegmatogenous retinal detachment: incidence and outcome. Retina. 2012;32(7):1350-1355.

16. Messmer E, Bronfeld N, Oehlschölger U, Heinrich T, Foester MH, Wessing A. Epiretinal membrane formation after pars plana vitrectomy in proliferative diabetic retinopathy. Klin Monbl Augenheilkld. 1992;200(4):207-272.
17. Mahapatra SK, Rao NG. Visual outcome of pars plana vitrectomy with intraocular foreign body removed through sclerocorneal tunnel and sulcus-fixated intraocular lens implantation as a single procedure in cases of metallic intraocular foreign body with traumatized cataract. India J Ophthalmol. 2010;58(2):115-118.

18. Pion B, Valyi ZS, Jansseens X, et al. Vitrectomy in uveitis patients. Bull Soc Belge Opthalmol. 2013;322:55-61.

19. Bovey EH, Herbot CP. Vitrectomy in the management of Uveitis. Ocul Immunol Inflamm. 2000;8:285-291.
Clinical Ophthalmology

\section{Publish your work in this journal}

Clinical Ophthalmology is an international, peer-reviewed journal covering all subspecialties within ophthalmology. Key topics include: Optometry; Visual science; Pharmacology and drug therapy in eye diseases; Basic Sciences; Primary and Secondary eye care; Patien Safety and Quality of Care Improvements. This journal is indexed on

Submit your manuscript here: http://www.dovepress.com/clinical-ophthalmology-journal

\section{Dovepress}

PubMed Central and CAS, and is the official journal of The Society of Clinical Ophthalmology (SCO). The manuscript management system is completely online and includes a very quick and fair peer-review system, which is all easy to use. Visit http://www.dovepress.com/ testimonials.php to read real quotes from published authors. 